\title{
卫星资料揭示的春季黑潮海区海洋对大气的影响及其 机制研究
}

\author{
徐海明, 王琳玮, 何金海
}

南京信息工程大学大气科学学院, 江苏省气象灾害重点实验室, 南京 210044

E-mail: hxu@nuist.edu.cn

2007-09-04 收稿, 2008-01-02 接受

国家重点基础研究发展计划(批准号: 2006CB403607)、国家自然科学基金(批准号: 40575045)和“中国气候系统的协同观测与预测研究”项目(批 准号: GYHY200706005)资助

摘要 采用最新的高分辨率卫星观测资料研究了春季西北太平洋黑潮海区海洋与大气之 间的关系, 特别是海洋锋区上海气之间的关系. 资料分析表明, 黑潮海洋锋区上海温与 海表面风速之间存在明显的正相关关系, 特别是当海洋锋区强并在其上产生明显的海洋 波动时, 海温与海表面风速之间的正相关关系表现得更为显著. 这种海温与海表面风速 之间的正相关关系与太平洋海盆尺度的海温与海表面风速之间的负相关关系正好相反, 清楚反映了春季黑潮海区海气之间表现为海洋对大气的作用. 随后, 采用一个高分辨率 的区域大气模式进一步研究了海洋影响大气的可能机制. 数值模拟表明, 黑潮海区海洋 锋区上海温变化可通过影响大气边界层稳定度以及边界层垂直混合来影响海表面的风 速, 即海温升高时大气边界层稳定性减弱, 垂直混合增强, 从而把高层较大风速带至海 表面, 海表面风速增强; 反之, 海温降低则大气边界层稳定性增强, 垂直混合受到抑制, 海表面风速减少.

关键词

卫星资料

黑潮海区

海洋锋

春季

海洋对大气的影响
在低纬度和热带海表面温度相对较高的暖洋面 上, 海温的变化往往通过引起深对流的调整从而对 大气环流产生影响, 而这种深对流调整主要表现为 第一斜压模态结构 [1 3]. 所以, 在热带暖洋面上, 海 温、深对流以及海表面风场之间存在很好的耦合关系, 正是这种海气之间的关系可以很好地用来解释像 ENSO这样的热带海气相互作用的现象 ${ }^{[4]}$.

在海温相对较低的中高纬洋面上, 相对而言深 对流较少出现, 大气对海温变化的调整明显不同于 海温较高的热带洋面上 ${ }^{[5]}$. 长期以来, 人们对中纬度 地区的海气相互作用进行了广泛的研究 ${ }^{[6 ~ 9]}$. 大量研 究表明海盆尺度的太平洋海表面温度与海表面风速 存在显著的负相关 ${ }^{[8]}$. 人们发现冬季负(正)海温异常 往往出现在海表面盛行风风速增强(减弱)的地区 ${ }^{[10,11]}$, 这种海温与海表面风速之间的负相关关系表明了大
气对海洋的强迫作用 [12], 而这种大气对海洋的强迫 作用明显可通过海表面感热和潜热通量来解释 [13 15].

至于中纬度海洋对大气的反馈作用一直缺乏有 效的观测证据, 其原因在于: 一方面, 中纬度地区有 频繁的天气尺度系统的活动, 另一方面缺乏长时间 和高分辨率的观测资料. 以往的研究主要通过大尺 度的相关关系来讨论中高纬海洋对大气的影响. Namias ${ }^{[16]}$ 发现夏季阿留申地区的海温异常与后期大 气环流存在显著的相关, 表明海洋对大气可能存在 影响. 赵永平等人 ${ }^{[17,18]}$ 也指出, 冬季黑潮海域海洋异 常加热对后期海平面气压和 $500 \mathrm{hPa}$ 高度场都存在一 定的影响. 通过计算黑潮海区海温与海平面气压的 滞后相关, Liu和 $\mathrm{Wu}^{[19]}$ 指出在秋季黑潮海区可能存在 大气对海温的响应. 最近, Frankignoul等人 [20]采用滞 后最大协方差分析方法, 指出在夏末和秋末初冬北 
太平洋存在海温异常对大尺度大气环流的影响. 至 于海洋是如何影响大气的, 其影响的过程和机理如 何还没有得到很好解释.

20 世纪 90 年代后期, 全球大气环流模式被广泛 用来研究大气对中高纬海温异常的响应. 研究表明, 大气对海温异常的响应很大程度取决于大气的基本 状态和海温异常的位置, 由于基本状态的不同, 相同 的海温异常可以导致完全不同的大气响应 [21]. 至于 在大气环流模式中大气是如何响应海温异常的, 到 目前为止仍没有达成共识 ${ }^{[22,23]}$.

海洋锋区 (类似于大气中的锋区，表现为海表面 水平温度梯度大的狭窄区域)提供了一个独一无二的 机会来研究海洋对大气的反馈作用. 海洋锋区通常 与强海流相联系, 海流的水动力不稳定导致了海洋 锋区产生波动从而引起海温变化. 由于海洋锋区本 身较窄(约几十千米)而且往往出现在远离海岸的大 洋海上, 常规的观测很难监测到. 近年来, 大量高分 辨率的卫星观测资料使人们研究海洋锋区上的海气 相互作用特征成为可能 [24 26]. Hashizume等人 ${ }^{[25]}$ 利用 高分辨率的卫星资料研究了赤道东太平洋海洋锋区 上海洋不稳定波引起的大气变化, 他们的观测研究 清楚地揭示了海温与海表面风速显著的正相关关系， 这种海温与海表面风速之间的正相关与冬季中高纬 海温与风速之间负相关关系刚好相反.

本研究的目的就是要利用最新的高分辨率卫星 观测资料, 研究西北太平洋黑潮海区海洋锋区上的 海气之间的关系, 特别是南北两条锋区上海温与海
表面风场之间的关系，然后再采用一个高分辨率的 区域大气模式来模拟研究大气对海洋的响应过程及 机理.

\section{1 资料}

2002 年, 美国宇航局发射了 Agua 卫星, 该卫星 载有先进的微波扫描辐射仪 (advanced microwave scanning radiometer, AMSR), AMSR 可对每天的海表 面温度作全天候的观测, 同时把观测范围扩展到 全球并提高了观测精度, AMSR 同时也观测每天全球 的海表面风速、降水率、整层大气的云中液态水含量、 整层大气的水汽量等. 本文中, 我们采用 2003 年 1 月至 2006 年 12 月 4 年的 AMSR 全球月平均海温 场和海表面风速场, 水平分辨率为 $0.25^{\circ} \times 0.25^{\circ}$ 经 纬度.

1999 年 7 月, 美国宇航局发射了一颗专门用来 观测海表面风场的Quick Scatterometer(简称QuickSCAT)卫星, 该卫星搭载的微波散射仪可观测每天全 球海洋上的海表面 $10 \mathrm{~m}$ 高处风矢量场 [24]. 为与 AMSR观测时段相一致, 我们采用 2003 年 1 月到 2006 年 12 月的QuickSCAT月平均风场, 水平分辨率 为 $0.25^{\circ} \times 0.25^{\circ}$ 经纬度.

\section{2 观测资料分析}

\section{1 多年平均}

图 1(a)给出了 2003 2006 年春季(3 4 月)平均的 AMSR 海表面温度和海表面 10 米高处的风速. 尽管 已取了 4 a 资料的平均, 但从图 1(a)中还可以清楚看

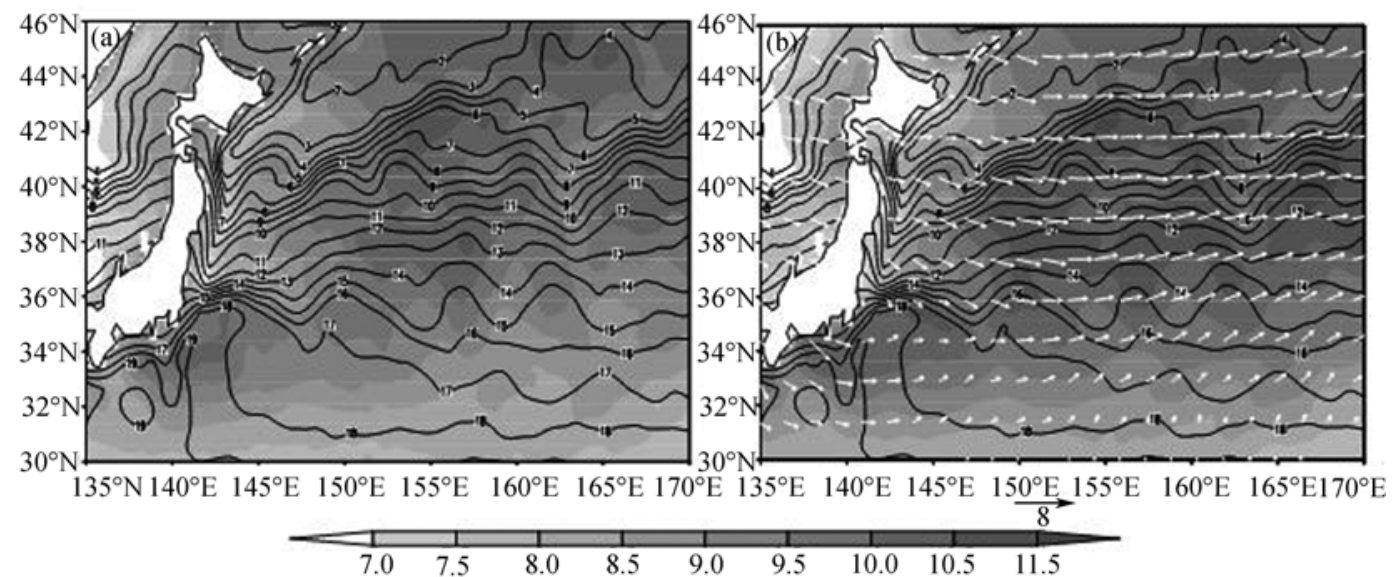

图 $12003 \sim 2006$ 年 3 4 月平均的海表面温度(等值线, 单位: ${ }^{\circ} \mathrm{C}$ )和风速(阴影，单位: $\mathrm{m} / \mathrm{s}$ ) (a) AMSR 海表面温度和风速; (b) AMSR 海表面温度和 QuickSCAT 风速, 下同 
到, 在日本以东的洋面上仍然明显存在南北两条海 洋锋区. 南锋区位于 $35^{\circ} \mathrm{N}$ 附近, 自日本沿海向东呈 波状形式, 形成明显的暖脊、冷槽, 其波长约为 600 $800 \mathrm{~km}^{[27,28]}$, 研究已表明这些锋区上的波动主要是 由黑潮急流的动力不稳定所造成的 $[29,30]$. 比较锋区 上的海洋波动与AMSR卫星资料观测的海表面风速 的分布, 不难发现海表面风速与锋区上海温的冷暖 分布存在很好的一一对应关系, 在暖的温度脊上空, 对应于海表面风速的大值区, 而冷的温度槽上空则 对应于风速的小值区. 例如, 位于 $150^{\circ} \mathrm{E}, 35^{\circ} \mathrm{N}$ 附近 为一明显的暖脊, 明显对应于一风速大于 $9 \mathrm{~m} / \mathrm{s}$ 的大 风速区, 而在东西两侧的冷槽区 $\left(147^{\circ} \mathrm{E}, 35^{\circ} \mathrm{N}\right.$ 和 $155^{\circ} \mathrm{E}, 35^{\circ} \mathrm{N}$ 附近) 风速明显减弱. 这种暖海温对应于 海表面风速增强、冷海温对应于海表面风速减少的关 系同样清楚地反映在位于 $40^{\circ} \mathrm{N}$ 附近的北锋区上. 尽 管北锋区的走向与南锋区的东西向明显不同, 呈西 南-东北走向, 其上的波动振幅和波长也明显小于南 锋区上波动振幅和波长, 但同样可以清楚可到, 锋区 上暖脊上空明显对应于海表面风速的大值区，而冷 槽上空对应于海表面风速的小值区.

为了进一步验证上述海温与海表面风速之间关 系的可信性, 图 1(b)给出了 QuickSCAT 卫星同期观 测的海表面 $10 \mathrm{~m}$ 高处的风矢量和风速场. 比较图 1(a) 和 (b), 不难发现, 尽管 QuickSCAT 卫星采用与 AMSR 完全不同的遥感器, 但是除 QuickSCAT 卫星 观测到的海表面风速略大于 AMSR 风速外, 其观测 到的海表面风速分布与 AMSR 观测的风速基本一致. 从图 1(b)中同样可以清楚看到, 南北两条海洋锋区上 暖脊处都对应于风速增强、冷槽处对应于风速减弱. 从图 1(b)还可以看到, 春季黑潮海区盛行西北偏西风, 在南锋区上主要表现为西风不断穿越冷槽和暖脊, 当西风从冷槽吹向暖脊时西风明显加速, 而当西风 从暖脊吹向冷槽时则西风明显减速. 在北锋区上, 由 于锋区呈西南-东北走向, 风场更多地表现为穿越海 洋锋区, 由锋区北侧的冷海水区穿越锋区吹向锋区 南侧的暖海水区，当穿越海洋锋区时，西风表现为明 显的加速.

图 2 给出了黑潮主要海区 $\left(146^{\circ} \mathrm{E} 166^{\circ} \mathrm{E}, 32^{\circ} \mathrm{N} \sim\right.$ $\left.38^{\circ} \mathrm{N}\right) \mathrm{AMSR}$ 海温距平与 QuickSCAT 海表面风速距平 的散点图分布. 图中距平值则由某一点的值与以该 点为中心的 31 点纬向平均值相减而得, 目的是为了 突出锋区上海洋波动的特征. 由图可见, 锋区上海温
与海表面风速之间存在明显的正相关关系，相关系 数达到 0.42. 这种海温与海表面风速之间存在的正相 关关系与北太平洋海盆尺度的海温与海表面风速之 间存在的负相关关系 ${ }^{[10]}$ 刚好相反, 表明黑潮海区明 显存在有别于海盆尺度的海气关系. 已有研究表明, 北太平洋海盆尺度的海温与海表面风速之间的负相 关关系从物理过程上可解释为大气对海洋的影响 [14,15], 即海表面风场通过海表面的感热通量和潜热 通量对其下的海表面温度产生影响(如强海表面风速 可通过强烈的蒸发冷却使海温降低, 反之, 则相反), 而春季黑潮海洋锋区上海温与海表面风速之间存在 的正相关关系可能更多地反映了海洋对大气的影响. 至于黑潮海洋锋区上海温变化如何影响其上的海表 面风速, 其过程和机理如何, 我们将在第 3 节中加以 讨论.

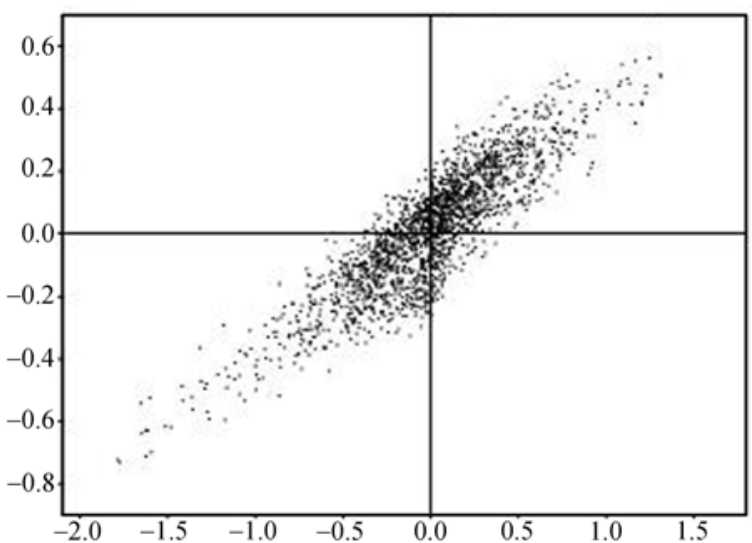

图 $22003 \sim 2006$ 年 3 4 月平均的 AMSR 海表面温度和 QuickSCAT 风速在黑潮海区 $\left(146 \sim 166^{\circ} \mathrm{E}, 32 \sim 38^{\circ} \mathrm{N}\right)$ 的散点 分布

图中的海温和风速已取距平值, 即取某点的值与以该点为中心的 31 点纬向平均值的差. 横坐标为海温 (单位: ${ }^{\circ} \mathrm{C}$ ), 纵坐标为风速 (单位: $\mathrm{m} / \mathrm{s}$ )

\section{2 年际变化}

前面我们从多年气候平均场上讨论了黑潮海区 海表面温度与海表面风速之间的关系, 揭示了两者 之间的正相关关系, 但事实上西北太平洋黑潮海区 的海流存在明显的年际变化 ${ }^{[31]}$, 同样海温也存在明 显的年际变化 ${ }^{[32]}$.

图 3 给出了 2003 2006 年每年 3 4 月平均的 AMSR 海温和 QuickSCAT 海表面风场. 由图可见, 在 这 $4 \mathrm{a}$ 中黑潮海区的海温分布确实存在明显的年际变 化, 特别是位于 $35^{\circ} \mathrm{N}$ 附近的南海洋锋区在这 4 a 


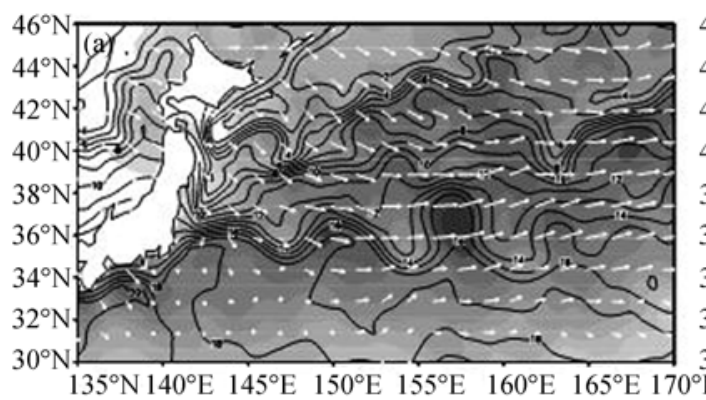

$135^{\circ} \mathrm{N} 140^{\circ} \mathrm{E} 145^{\circ} \mathrm{E} 150^{\circ} \mathrm{E} 155^{\circ} \mathrm{E} \quad 160^{\circ} \mathrm{E} \underset{9}{16}$

7.07 .58 .08 .59 .09 .510 .010 .511 .011 .512 .0

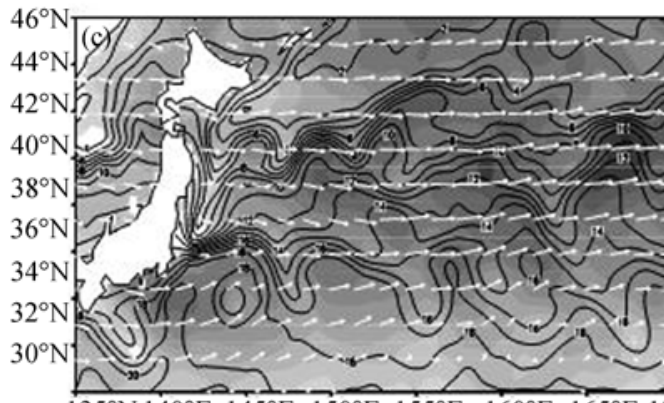

$135^{\circ} \mathrm{N} 140^{\circ} \mathrm{E} 145^{\circ} \mathrm{E} 150^{\circ} \mathrm{E} 155^{\circ} \mathrm{E} 10^{\circ} \mathrm{E} \frac{1}{10}$

7.07 .58 .08 .59 .09 .510 .010 .511 .011 .512 .0

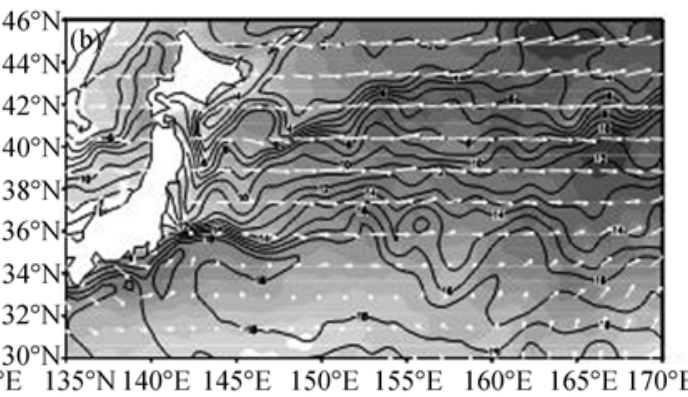

$\overrightarrow{10}$

$\frac{1}{7.07 .58 .08 .59 .09 .510 .010 .511 .011 .512 .0}$

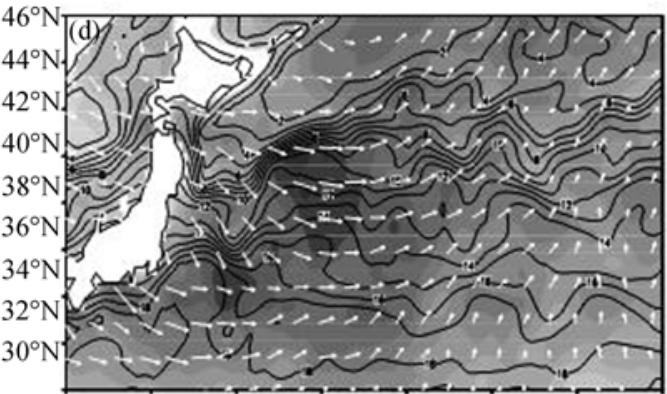

$135^{\circ} \mathrm{N} 140^{\circ} \mathrm{E} 145^{\circ} \mathrm{E} 150^{\circ} \mathrm{E} 155^{\circ} \mathrm{E} 160^{\circ} \mathrm{E} 165^{\circ} \mathrm{E} 170^{\circ} \mathrm{E}$

7.07 .58 .08 .59 .09 .510 .010 .511 .011 .512 .0

图 33 月 月平均 AMSR 海表面温度(等值线, 单位: ${ }^{\circ} \mathrm{C}$ )和 QuikSCAT 海表面 $10 \mathrm{~m}$ 风速(阴影, 单位: $\mathrm{m} / \mathrm{s}$ ) (a) 2003 年; (b) 2004 年; (c) 2005 年; (d) 2006 年

中明显表现为不同的形式. 在 2003 和 2005 年两年中, 在 $35^{\circ} \mathrm{N}$ 附近维持较强的海洋锋区, 并在其上形成明 显的海洋波动, 构成明显的暖脊和冷槽, 而在 2004 年和 2006 年两年中, 南部的海洋锋区仅出现在日本 沿海附近, 在 $150^{\circ} \mathrm{E}$ 以东的远海上海洋锋区已不再明 显, 也没有出现 2003 年和 2005 年那样的海洋波动, 只出现了一些振幅和波长都较小的不规则波动. 比 较这 4 a 南锋区上海温和海表面风速(图中阴影区)分 布, 不难发现在 2003 和 2005 年这两年具有明显海洋 波动的年份, 海表面温度与海表面存在很好的- 对应关系, 大的风速都出现在暖脊上, 而小风速区都 出现在冷槽上. 相对而言, 海洋波动不明显的 2004 和 2006 年, 海温与海表面风速之间的关系不像 2003 和 2005 年那样显著.

与南锋区存在明显的年际变化所不同, 在 2003 2006 年的 $4 \mathrm{a}$ 中, 在 $40^{\circ} \mathrm{N}$ 附近都维持一呈西南至东 北走向的较强的海洋锋区, 并在锋区上形成一些暖 脊和冷槽的海洋波动. 从图 3 中可以清楚看到, 海温 与海表面风速之间存在很好的一一对应关系, 大风 速区位于暖脊上, 而小风速区出现在冷槽上空.
从以上的分析可知, 西北太平洋黑潮海区海温 与海表面风速之间存在明显的正相关关系, 但这种 正相关关系的强弱明显依赖于海洋锋区的强弱以及 锋区上产生的海洋波动. 当海洋锋区强, 并在其上产 生明显的海洋波动时, 海表面盛行风不断穿越海洋 锋区和冷暖槽脊, 在暖脊上空风速增强, 冷槽上空风 速减小, 从而使海温与海表面风速之间形成很好的 正相关关系; 而当海洋锋区较弱或锋区上海洋波动 不显著时, 海温与海表风速之间的正相关关系则变 得不明显.

\section{3 数值模拟}

关于冷水区(海温低于能引起深对流的海区, 一 般海温低于 $\left.26 \sim 27^{\circ} \mathrm{C}\right)$ 海表面温度如何影响和改变海 表面风场, 到目前为止, 主要存在两种不同的机制. 一种是 1987 年Linzen和Nigam ${ }^{[33]}$ 提出的海平面气压 机制, 即海温通过影响海表面气压来改变海表面风 场. 海温的升高使边界层空气增暖、海平面气压相应 下降, 而海温的降低则使边界层空气变冷、海平面气 压上升, 海平面气压场的改变则驱动海表面风场发 
生改变. 另一种则是由 1989 年Wallace等人 ${ }^{[34]}$ 提出的 近表面动量垂直混合机制, 即海温升高使大气边界 层的稳定性减弱, 垂直混合增强, 从而把高层较大风 速带至海表面, 导致海表面风速增强; 反之, 海温降 低则使大气边界层的稳定性增强, 垂直混合受到抑 制, 海表面风速减少. 根据以上两种不同的机制, 当 动量垂直混合机制在起作用时, 海温与海表面风速 之间应具有同位相的变化关系; 而当海平面气压机 制在起作用时, 海温与风速之间存在明显的 $90^{\circ}$ 位相 差 ${ }^{[35]}$. 从前面卫星资料的分析结果来看, 黑潮海区 海洋锋区上的海温与海表面风速之间具有明显的同 位相关系, 可见在黑潮海洋锋区上动量垂直混合机 制起了主要的作用. 由于缺乏高分辨率的大气观测 资料, 无法从资料分析上来验证这种海洋影响大气 的机制, 为此, 本节中, 我们将采用一个高分辨率的 区域大气模式来模拟研究黑潮海区大气对海温的响 应, 并探讨海洋影响大气的可能机制.

\section{1 数值模式和试验方案}

本文采用的模式是美国夏威夷大学国际太平洋 研究中心最近发展的区域大气模式. 关于该模式的 详细介绍以及它对东亚夏季气候的模拟能力可参阅 Wang等人 ${ }^{[36]}$ 的文献. 该模式已被广泛用来研究南美 安第斯山脉和中美洲山脉对东太平洋气候的影响 [37,38], 以及大气对赤道中东太平洋海洋不稳定波的 响应 ${ }^{[39]}$.

在本试验中, 模式范围取为 $130^{\circ} \sim 180^{\circ} \mathrm{E}, 20^{\circ} \sim$ $50^{\circ} \mathrm{N}$ 的西北太平洋地区, 水平分辨率为 $0.25^{\circ} \times 0.25^{\circ}$ 经纬度. 在这里我们采用每天一次的高分辨率 $\left(0.25^{\circ}\right.$ $\times 0.25^{\circ}$ 经纬度)AMSR 海温场作为模式的底边界条件. 模式的初边界条件采用水平分辨率为 $2.5^{\circ} \times 2.5^{\circ}$ 经纬
度的 NCEP/NCAR 再分析资料. 模式从 2005 年 3 月 1 日 $00 \mathrm{Z}$ 开始积分, 一直运行到 4 月 30 日, 共积分 2 个月.

\section{2 模拟结果分析}

图 4 分别给出了 2005 年 3 4 月 QuickSCAT 观测 的海表面风速和模式模拟的模式最低层 $(\sigma=0.997$, 相当于海表面)的风速(图中阴影区). 由图可见, 模式 非常好地模拟出了海表面风场的分布, 与观测相比 (图 4(a)), 模式模拟的海表面风速除了比 QuickSCAT 卫星观测的风速略小以外，与观测相当的一致. 特别 是在南北两个海洋锋区上, 模式非常逼真地模拟出 了海表面风速与海温之间的正相关关系, 即大风速 区出现在海洋锋的暖脊上, 小风速区出现在冷槽上 空.

图 5 给出了模式模拟的风速和假相当位温沿 $40.5^{\circ} \mathrm{N}(\sim$ 北海洋锋区)垂直剖面图. 由图可见, 大气对 海洋锋区上海温变化的响应并不仅局限于海表面, 其响应可一直向上扩展到对流层低层约 $900 \mathrm{hPa}(\sim \sigma$ 为 0.90$)$ 附近. 在北海洋锋区上, 高海温区对应于高 层大风速区的向下扩展, 相对而言, 低海温区高层风 速向下的扩展明显受到抑制. 另外, 从图中假相当位 温随高度的变化可以看到, 对于相邻的高低海温区 而言, 在高海温区上空往往形成一假相当位温随高 度保持不变的深厚混合层, 而低海温区则在靠近海 表面的形成一假相当位温的小值区，其位温向上则 迅速增加, 表明大气稳定度较暖海水区明显增加、边 界混合层高度相应变浅.

为了更清楚地表征大气边界层中大气稳定度和 风速变化的关系, 我们在北海洋锋区 $40.5^{\circ} \mathrm{N}$ 上选取 相邻冷暖槽脊的 $147.5^{\circ} \mathrm{E}$ 和 $150.0^{\circ} \mathrm{E}$ 两点(图 6), 绘出
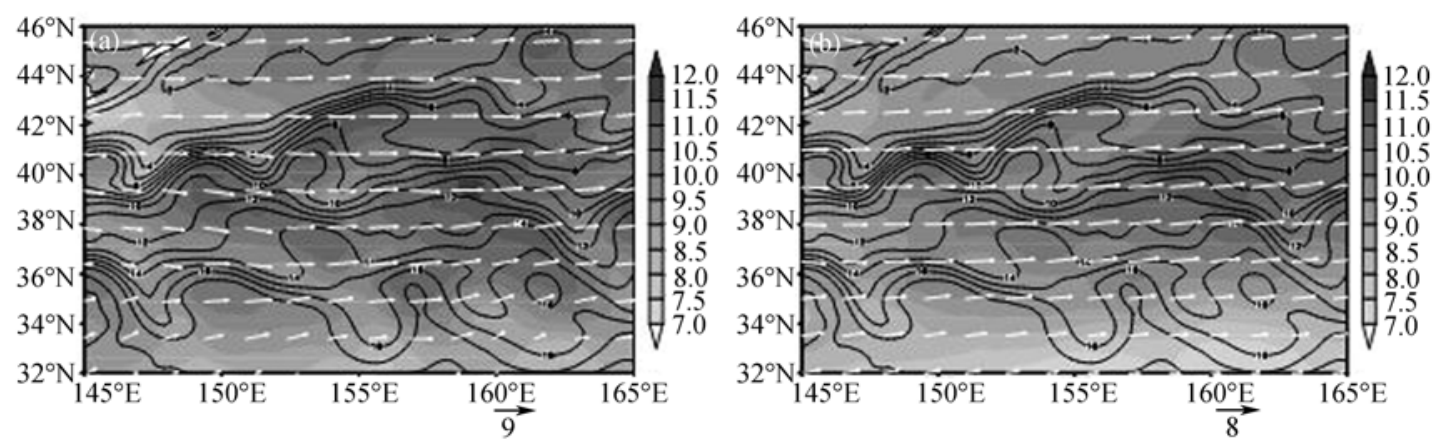

图 42005 年 3 4 月平均的 QuickSCAT 海表面风场(a)和模式模拟的 0.997 模式 $\sigma$ 层上的风场(b)

(a) AMSR 海表面温度和风速; (b) AMSR 海表面温度和模式风速. 图中阴影区表示风场, 单位: $\mathrm{m} / \mathrm{s}$. 图中同时也给出了 2005 年 3 4 月平均的 AMSR 海表面温度(等值线, 单位: ${ }^{\circ} \mathrm{C}$ ) 


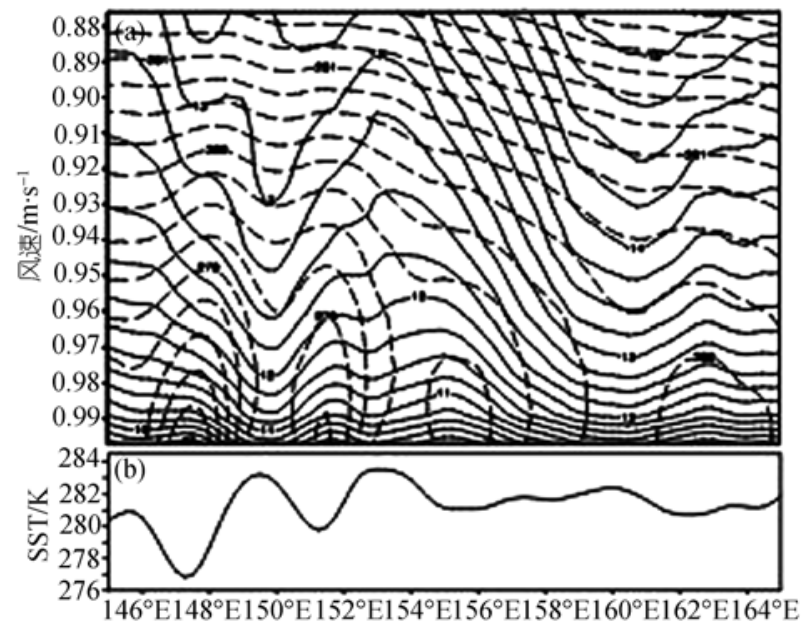

图 5

(a) 模式模拟的 2005 年 3 4 月平均的风速(实线)和假相当位温(虚 线, 单位: K)沿 $40.5^{\circ} \mathrm{N}$ 的垂直剖面; (b) 给出了 2005 年 $3 \sim 4$ 月平 均的海表面温度(单位: $\mathrm{K}$ )沿 $40.5^{\circ} \mathrm{N}$ 的纬向变化

它们的垂直廓线. 由图暖脊上空的假相当位温明显 高于冷槽上空, 冷槽上空主要表现为假相当位温随 高度增加的稳定性层结(图 6(b)), 而在暖脊上空, 在 海表面至 0.99 的 $\sigma$ 层之间出现了假相当位温随高度 减少的不稳定层结, 在 0.99 至 0.98 的 $\sigma$ 层之间则出 现了假相当位温随高度不变的中性层结, 稳定性明 显减弱. 暖脊上空稳定性的减弱则促使高层强风速 向下扩展, 风速明显增强(图 6(a)). 相比可得暖脊上 空大气的稳定性较冷槽上空的大气稳定性明显减弱, 相应地暖脊上空的风速明显大于冷槽上空的风速(图 6(a)). 这种冷暖槽脊上空边界层大气稳定性以及垂 直混合的强弱差异同样清楚地反映在模式模拟的大

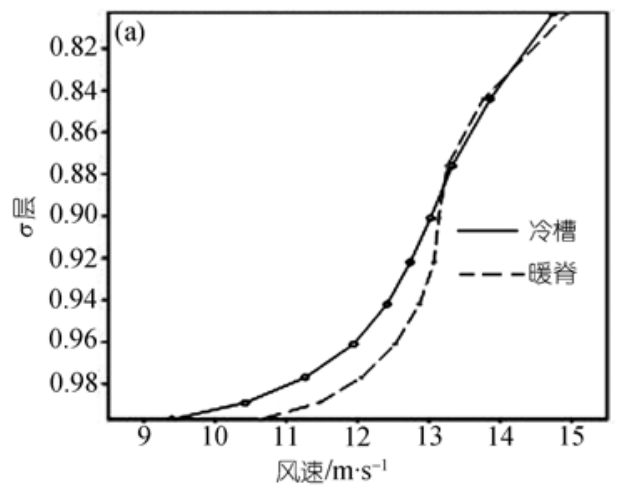

气边界层高度上(图略), 模式模拟的边界层高度场与 海洋锋区上冷暖槽脊存在很好的一一对应关系, 暖 脊上空为一致的边界层高度高值区而冷槽则对应于 边界层高度场的低值区, 清楚表明海洋锋区上海洋 波动通过改变边界层大气的稳定性和垂直混合强弱 从而对边界层风场产生影响.

\section{4 结论和讨论}

本文首先采用最新的高分辨率卫星观测资料研 究了春季西北太平洋黑潮海区海洋与大气之间的关 系, 特别是海洋锋区上海气之间的关系. 在春季, 日 本以东的黑潮海区存在南北两条海洋锋区, 南部海 洋锋区位于 $35^{\circ} \mathrm{N}$ 附近, 明显呈东西走向, 而北部海 洋锋区则位于 $40^{\circ} \mathrm{N}$ 附近, 呈明显的东北至西南走向. 海洋的动力不稳定使海洋锋区产生波动, 形成明显 的冷槽和暖脊. 资料分析表明, 南北海洋锋区上海温 与海表面风速之间都存在明显的正相关关系, 即高 海温区与海表面的大风速相对应, 低海温区则对应 于小风速区, 特别是当海洋锋区强并在其上产生明 显的海洋波动时, 海温与海表面风速之间的正相关 关系表现得更为明显. 这种海温与海表面风速之间 的正相关关系与反映大气对海洋影响的太平洋海盆 尺度海温与海表面风速之间的负相关关系正好相反, 反映了春季黑潮海区大气与海洋之间主要表现为海 洋对大气的强迫作用.

采用一个高分辨率的区域大气模式进一步研究 了海洋影响大气的可能机制. 当用一天 4 次的 NCEP/ NCAR 再分析资料和逐日的 AMSR 海温分别作为模 式的侧边界和底边界条件来强迫大气模式时, 模式

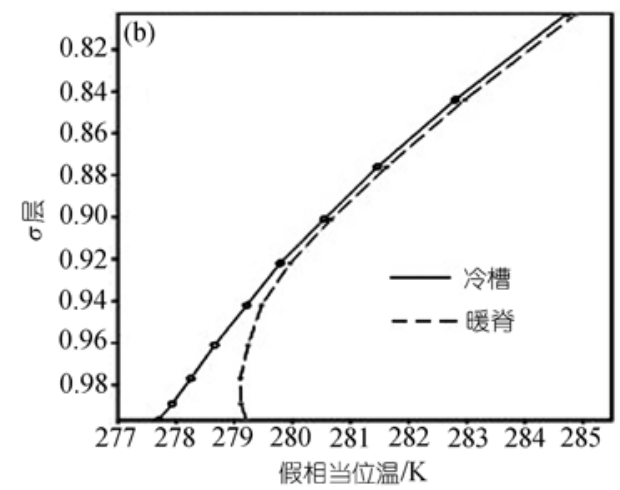

图 6 模式模拟的风速 $(\mathrm{a})$ 和假相当位温 $(\mathrm{b})$ 在 $40.5^{\circ} \mathrm{N}, 147.5^{\circ} \mathrm{E}$ (实线)和 $40.5^{\circ} \mathrm{N}, 150.0^{\circ} \mathrm{E}$ (虚线)2 点上的 垂直邡线

图中风速和假相当位温均为 2005 年 3 4 月 2 月的平均值 
很好地再现了春季黑潮海区海温与海表面风速之间 的正相关关系, 并与观测结果相一致. 进一步分析表 明, 海洋锋区上的海洋波动可明显改变其上大气边 界层中的稳定度和垂直混合强弱, 高海温区对应于 大气边界层稳定度的减弱, 低海温区则对应于大气 边界层稳定度的增强, 表明黑潮海区海洋锋区上海 温变化可能主要通过影响大气边界层稳定度和垂直 混合强弱对海表面的风场产生影响, 即海温升高使 大气边界层的稳定性减弱, 垂直混合增强, 从而把高 层较大风速带至海表面, 导致海表面风速增强; 反之, 海温降低则使大气边界层的稳定性增强, 垂直混合 受到抑制, 海表面风速减少. 这与Wallace等人 ${ }^{[34]}$ 提 出的边界层垂直混合机制相一致, 这种垂直混合机 制已被广泛地用来解释大气边界层风场对赤道中东 太平洋海洋不稳定波的响应 ${ }^{[24,25]}$, 同时也被穿越海 洋不稳定波的船舶高空观测资料所证实 ${ }^{[40]}$.
本文仅从边界层中垂直混合调整的角度探讨了 海表面风场对海温异常的响应. 在实际过程中, 边界 层风场对海温异常的响应过程可能要比本文所揭示 的要复杂的多. 在海表面风场对海温异常的响应过 程中, 除了边界层垂直混合过程外, 风场的改变还可 能与动量方程中的其他项的作用, 如气压梯度力、风 的水平平流以及科氏力的作用有关. Small等人 ${ }^{[39]}$ 用 区域大气模式模拟研究了大气对赤道中东太平洋上 热带不稳定波的响应, 发现边界层风场对海洋不稳 定波的响应过程中, 除了边界层垂直混合调整以外, 气压梯度力、风的水平平流也都起了一定的作用. 位 于不同纬度的海洋波动, 大气对它们的响应会存在 明显的不同, 至于大气是如何响应中高纬黑潮海洋 锋区上海洋波动的, 我们将根据模式输出的结果, 对 动量方程中的各项作详细的分析研究, 所得结果将 另文发表.

\section{参考文献}

Matsuno T. Quasi-geostrophic motions in equatorial areas. J Meteor Soc Japan, 1966, 2: 25-43

Gill A E. Some simple solutions for heat-induced tropical circulation. Quart J Roy Meteor Soc, 1980, 106: 447-462[doi]

Neelin J D, Held I M. Modeling tropical convergence based on the moist static energy budget. Mon Weather Rev, 1987, 115: 312[doi]

Neelin J D, Battisti D S, Hirst A C, et al. ENSO theory. J Geophys Res, 1998, 103: 14261 - 14290 [doi]

Xie S P. Satellite observations of cool ocean-atmosphere interaction. Bull Amer Meteor Soc, 2004, 85: 195-208[doi]

Namias J. Large-scale air-sea interactions over the North Pacific from summer 1962 through the subsequent winter. J Geophys Res, 1963, 68: 6171-6186

Davis R E. Predictability of sea surface temperature and sea level pressure anomalies over the North Pacific Ocean. J Phys Oceanogr, 1976, 6: 249-266[ [doi]

Namias J, Cayan D R. Large-scale air-sea interactions and short period climate fluctuations. Science, 1981, 214: 869-876[doi]

赵永平, 陈永利, 翁学传. 中纬度海气相互作用研究进展. 地球科学进展, 1997, 12(1): 32-36

Wallace J M, Smith C, Jiang Q. Spatial patterns of atmosphere-ocean interaction in the northern winter. J Clim, 1990, 3: 990-998[doi]

秦正坤, 孙照渤. 冬季风异常对西北太平洋海温影响的区域性特征. 大气科学, 2006, 30(2): 257-267

Frankignoul C. Sea surface temperature anomalies, planetary waves, and air-sea feedback in the middle latitudes. Rev Geophys, 1985 , 23: $357-390$ [doi]

赵永平. 北太平洋中纬度海区热量交换对其上空大气环流的影响. 海洋与湖沼, 1986, 17(1): 57-65

Cayan D R. Latent and sensible heat flux anomalies over the northern oceans: Driving the sea surface temperature. J Phys Oceanogr, 1992, 22: 859-881 [doi]

Alexander M A, Blade I, Newman M, et al. The atmospheric bridge: The influence of ENSO teleconnections on air-sea interaction over the global oceans. J Clim, 2002, 15: 2205-2231 [doi]

Namias J. Negative ocean-air feedback systems over the Northern Pacific in the transition from warm to cold seasons. Mon Weather Rev, 1976, 104: 1107-1121 [doi]

赵永平, McBean G A. 黑潮海域海洋异常加热对后期大气环流的影响. 海洋与湖沼, 1996, 27(3): 246一250

赵永平, McBean G A. 冬季中纬度海气相互作用与长江中下游汛期旱涝预测. 海洋科学集刊, 1996, 37: 19-24

Liu Z, Wu L. Atmospheric response to North Pacific SST: The role of ocean-atmosphere coupling. J Clim, 2004, 17: 1859-1882[doi] 
20 Frankignoul C, Sennechael N. Observed influence of North Pacific SST anomalies on the atmospheric circulation. J Clim, 2007, 20: 592-606[doi]

21 Peng S, Robinson W A, Hoerling M P. The modeled atmospheric response to midlatitude SST anomalies and its dependence on background circulation states. J Clim, 1997, 10: 971-987 [doi]

Robinson W A. Review of WETS—The Workshop on Extratropical SST anomalies. Bull Amer Meteor Soc, 2000, 81: 567-577 [doi]

Kushnir Y, Robinson W A, Blade I, et al. Atmospheric GCM response to extratropical SST anomalies: Synthesis and evaluation. J Clim, 2002, 15: 2233-2256[doi]

24 Liu W T, Xie X, Polito P S, et al. Atmospheric manifestation of tropical instability waves observed by QuickSCAT and Tropical Rain Measuring Mission. Geophys Res Lett, 2000, 27: 2545-2548[ [doi]

Hashizume H, Xie S P, Liu W T, et al. Local and remote atmospheric response to tropical instability waves: A global view from space.

J Geophys Res, 2001, 106D: 10173-10185[doi]

Nonaka M, Xie S P. Covariations of sea surface temperature and wind over the Kuroshio and its Extension: Evidence for ocean-to-atmosphere feedback. J Clim, 2003, 16: 1404-1413 $\underline{\text { [doi] }}$

Tai C K, White W. Eddy variability in the Kuroshio Extension as revealed by Geosat altimetry: Energy propagation away from the jet, Reynolds stress, and seasonal cycle. J Phys Oceanogr, 1990, 20: 1761-1777 [doi]

Qiu B, Kelly K A, Joyce T M. Mean flow and variability in the Kuroshio Extension from Geosat altimetry data. J Geophys Res, 1991, 96: 18491-18507[doi]

Qiu B. Variability and energetics of the Kuroshio Extension and its recirculation gyre from the first two-year TOPEX data. J Phys Oceanogr, 1995, 25: 1827-1842 [doi]

30 Hurlburt H E, Wallcraft A J, Schmitz W J, et al. Dynamics of the Kuroshio/Oyashio Current system using eddy-resolving models of the North Pacific Ocean. J Geophys Res, 1996, 101: 941 - 976 [doi]

Kawabe M. Variations of current path, velocity, and volume transport of the Kuroshio in relation with the large meander. J Phys Oceanogr, 1995, 25: 3103-3117 [doi]

Taguchi B, Xie S P, Schneider N, et al. Decadal variability of the Kuroshio Extension: Observation and an eddy-resolving model hindcast. J Clim, 2007, 20: 2357-2377 [doi]

33 Lindzen R S, Nigam S. On the role of sea surface temperature gradients in forcing low level wind and convergence in the tropics. J Atmos Sci, 1987, 44: 2418-2436 [doi]

34 Wallace J M, Mitchell T P, Deser C. The influence of sea surface temperature on sea surface wind in the eastern equatorial Pacific: Seasonal and interannual variability. J Clim, 1989, 2: 1492-1499 [doi]

Hayes S P, McPhaden M J, Wallace J M. The influence of sea surface temperature on surface wind in the eastern equatorial Pacific. J Clim, 1989, 2: 1500-1506[이]

Wang Y Q, Sen O L, Wang B. A highly resolved regional climate model (IPRC-RegCM) and its simulation of the 1998 severe precipitation event over China. Part I: Model description and verification of simulation. J Clim, 2003, 16: 1721-1738 [doi]

37 Xu H M, Wang Y Q, Xie S P. Effects of the Andes on eastern Pacific climate: A regional atmospheric model study. J Clim, 2004, 17: $589-602$ [doi]

38 Xu H M, Xie S P, Wang Y Q, et al. Effects of Central American mountains on the eastern Pacific winter ITCZ and moisture transport. J Clim, 2005, 18: 3856-3873 [doi]

39 Small R J, Xie S P, Wang Y Q. Numerical simulation of atmospheric response to Pacific tropical instability waves. J Clim, 2003, 16: $3722-3737 \underline{\text { [doi] }}$

40 Hashizume H, Xie S P, Fujiwara M, et al. Direct observations of atmospheric boundary layer response to SST variations associated with Tropical instability waves over the eastern equatorial Pacific. J Clim, 2002, 15: 3379—3393 [doi] 